\title{
The Biotribology of PEEK-on-HXLPE Bearings Is Comparable to Traditional Bearings on a Multidirectional Pin-on-disk Tester
}

\author{
Doruk Baykal PhD, Ryan S. Siskey MSc, Richard J. Underwood PhD, \\ Adam Briscoe PhD, Steven M. Kurtz PhD
}

Published online: 25 July 2016

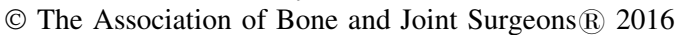

\begin{abstract}
Background All-polymer bearings involving polyetheretherketone (PEEK) have been proposed for orthopaedic applications because they may reduce stress shielding, reduce weight of the implants, reduce wear and risk of osteolysis, and prevent release of metal ions by replacing the metal articulating components. Little is known about the biotribology of allpolymer PEEK bearings, including the effects of cross-shear, which are relevant for implant longevity, especially in the hip,
\end{abstract}

One or more of the authors received institutional support from Smith \& Nephew (London, UK); Stryker (Kalamazoo, MI, USA); Zimmer Biomet (Warsaw, IN, USA); DePuy Synthes (Warsaw, IN, USA); Medtronic (Dublin, Ireland); Invibio (Lancashire, UK); Stelkast (McMurray, PA, USA); Formae (Paoli, PA, USA); Kyocera Medical (Osaka, Japan); Wright Medical Technology (Memphis, TN, USA); Ceramtec (Laurens, SC, USA); DJO (Vista, CA, USA); Celanese (Irving, TX, USA); Aesculap (Center Valley, PA, USA); Spinal Motion (Mountain View, CA, USA); Active Implants (Memphis, TN, USA); and Ferring Pharmaceuticals (Parsippany, NJ, USA).

All ICMJE Conflict of Interest Forms for authors and Clinical Orthopaedics and Related Research ${ }^{\mathbb{R}}$ editors and board members are on file with the publication and can be viewed on request.

Clinical Orthopaedics and Related Research ${ }^{\mathbb{B}}$ neither advocates nor endorses the use of any treatment, drug, or device. Readers are encouraged to always seek additional information, including FDAapproval status, of any drug or device prior to clinical use.

This work was performed at Exponent, Inc, Philadelphia, PA, USA.

D. Baykal ( $\square)$

Exponent, Inc, 149 Commonwealth Drive, Menlo Park,

CA 94025, USA

e-mail: dbaykal@exponent.com

R. S. Siskey, R. J. Underwood, S. M. Kurtz

Exponent, Inc, Philadelphia, PA, USA

A. Briscoe

Invibio, Inc, Lancashire, UK and increased temperature that may affect lubricant proteins and, hence, lubrication in the joint.

Questions/purposes Using pin-on-disk in vitro testing, we asked: (1) Can all-polymer bearing couples involving PEEK have a comparable or lower wear rate than highly crosslinked UHMWPE (HXLPE) on CoCr bearing couples? (2) Is the wear rate of PEEK bearing couples affected by the amount of cross-shear? (3) Is there a difference in wear mechanism and surface morphology for all-polymer bearing surfaces compared with UHMWPE (HXLPE) on CoCr?

Methods We simultaneously tested a total of 100 pin-ondisk couples $(n=10$ per bearing couple) consisting of three traditional metal-on-UHMWPE and seven polymer-onpolymer bearings for 2 million cycles under physiologically relevant conditions and in accordance with ASTM F732. Using analysis of variance, we analyzed the effect of bearing surface topography and cross-shear on wear rate. The changes in surface topography were evaluated using optical microscopy. Sample size was sufficient to provide $80 \%$ power to detect a difference of $1.4 \mathrm{~mm}^{3} / \mathrm{MC}$ in average wear rates of bearing couples.

Results The combined wear rates of all-polymer bearing couples were not different than traditional bearing couples. With the numbers available, the PEEK and HXLPE bearing couple had a mean wear rate (WR: mean $\pm \mathrm{SD}$ ) of $0.9 \pm$ $1.1 \mathrm{~mm}^{3} / \mathrm{MC}\left(95 \%\right.$ confidence interval [CI], $0.2-1.5 \mathrm{~mm}^{3} /$ $\mathrm{MC}$ ), which was not different than the wear rate of the $\mathrm{CoCr}$ and HXLPE bearing couple $\left(1.6 \pm 2.0 \mathrm{~mm}^{3} / \mathrm{MC}\right.$; $95 \% \mathrm{CI}, 0.4-2.8 \mathrm{~mm}^{3} / \mathrm{MC}$; mean difference $=0.73 \mathrm{~mm}^{3} /$ $\mathrm{MC}, \mathrm{p}=0.36)$. Bearing couples with PEEK reinforced with a carbon fiber (CFR-PEEK) counterface had higher wear rates $\left(14.5 \pm 15.1 \mathrm{~mm}^{3} / \mathrm{MC} ; 95 \% \mathrm{CI}, 9.1-20.0 \mathrm{~mm}^{3} / \mathrm{MC}\right)$ than bearing couples with a PEEK $\left(5.1 \pm 3.7 \mathrm{~mm}^{3} / \mathrm{MC}\right.$; $\left.95 \% \mathrm{CI}, 3.7-6.4 \mathrm{~mm}^{3} / \mathrm{MC}\right)$ or $\mathrm{CoCr}\left(4.1 \pm 2.7 \mathrm{~mm}^{3} / \mathrm{MC}\right.$; 
$95 \% \mathrm{CI}, 3.2-5.1 \mathrm{~mm}^{3} / \mathrm{MC}$ ) counterface (mean difference $=$ $9.5 \mathrm{~mm}^{3} / \mathrm{MC}, \mathrm{p}<0.001$; and mean difference $=10.4 \mathrm{~mm}^{3} /$ MC, $\mathrm{p}<0.001$, respectively). PEEK and HXLPE were insensitive to the cross-shear scenario in the contact mechanics (WR: $0.3 \pm 0.1 \mathrm{~mm}^{3} / \mathrm{MC}$ for PEEK pins [95\% CI, $0.2-0.3 \mathrm{~mm}^{3} / \mathrm{MC}$ ] [representing full cross-shear condition] and $0.0 \pm 1.0 \mathrm{~mm}^{3} / \mathrm{MC}$ for PEEK disks [95\% CI, -0.5 to $0.5 \mathrm{~mm}^{3} / \mathrm{MC}$ ] [representing limited cross-shear condition], mean difference $=0.3 \mathrm{~mm}^{3} / \mathrm{MC}, \mathrm{p}=0.23$; WR: $1.3 \pm 1.0 \mathrm{~mm}^{3} / \mathrm{MC}$ for HXLPE pins [95\% CI, 0.7-1.9 $\mathrm{mm}^{3} / \mathrm{MC}$ ] [full cross-shear] and $2.1 \pm 2.2 \mathrm{~mm}^{3} / \mathrm{MC}$ for HXLPE disks [95\% CI, $0.8-3.3 \mathrm{~mm}^{3} / \mathrm{MC}$ ] [limited crossshear], mean difference $=0.8 \mathrm{~mm}^{3} / \mathrm{MC}, \mathrm{p}=0.24$ ). Qualitatively, the surface morphology of UHMWPE appeared similar with PEEK or $\mathrm{CoCr}$ as a counterface, although it had a rougher appearance when coupled with carbon fiberreinforced PEEK. No transfer film was detected on the specimens.

Conclusions Our in vitro pin-on-disk data suggest that all-polymer bearings, especially PEEK-on-HXLPE bearing couples, may represent a viable alternative to traditional bearings with respect to their wear performance. Our results warrant further testing of all-polymer bearing couples in physiologically relevant joint simulator tests.

Clinical Relevance The in vitro pin-on-disk wear resistance of all-polymer bearings incorporating PEEK-onHXLPE warrants further investigation using joint simulator testing for their validation as useful, metal-free alternatives to traditional CoCr-on-HXLPE bearings for use in orthopaedic applications.

\section{Introduction}

All-polymer bearings have been proposed, especially for knee and finger joint replacements [6]. All-polymer bearings involving polyetheretherketone (PEEK) may reduce stress shielding, reduce weight of the implants, reduce wear and risk of osteolysis, prevent release of metal ions by replacing the metal articulating components, and may also be preferred for its ease of manufacturing [6, 20]. Because PEEK and ultrahigh-molecular-weight polyethylene (hereafter UHMWPE) are available in numerous formulations $[10,12]$, it is challenging to effectively survey these bearing couples using a large joint simulator. Over the past decade, physiologically relevant pin-on-disk testing has been increasingly used to screen bearing couples for use as orthopaedic implants [9]. Multidirectional pin-on-disk testers are now recognized to correctly rank UHMWPE biomaterial couples for hip arthroplasty in terms of their in vivo tribologic performance [7].

To characterize the biotribologic properties of all-polymer bearings, it is also important to study the effects of cross-shear on the wear rate. For example, the wear resistance of UHMWPE is known to depend on the amount of cross-shear [17, 19, 24]. Furthermore, multidirectional kinematics have been reported to be a requirement to effectively reproduce the wear mechanisms in UHMWPE from retrieved implant components, especially in THA $[3,24]$. On the other hand, less multidirectional articulation is considered to occur in TKA, in which the primary motion consists of rolling and sliding in flexion and extension [4]. Although the wear properties of various formulations of PEEK against $\mathrm{CoCr}$ and in all-polymer bearings have been investigated $[6,21,22]$, comparatively little is known about the effects of multidirectional sliding on its wear resistance [14]. Laux and Schwartz [14] reported that the wear resistance of PEEK depended on sliding track directionality in dry articulation. However, wear mechanisms under dry articulation are unlikely to be physiologically relevant.

It is also important to analyze the frictional heat generated in all-polymer bearings, because these testing artifacts may lead to lubricant protein precipitation [15]. The precipitation may result in a solid layer of precipitated proteins and protect the articulating surfaces from wear or it may result in the depletion of soluble proteins in the lubricant and result in increased wear. In an in vitro study, we previously found that there was an increase of $10^{\circ} \mathrm{C}$ in steady-state temperature (measured $0.5 \mathrm{~mm}$ away from articulating surfaces) and higher coefficient of friction when UHMWPE-PEEK articulation was compared with UHMWPE-CoCr articulation in a pin-on-disk tester (1st International PEEK Meeting, Philadelphia, PA, USA, 2013). Little is known about the effects of temperature rise and friction on wear properties of all-polymer bearings incorporating PEEK and UHMWPE biomaterials [18].

In this study, we compared all-polymer bearings involving PEEK with traditional bearing couples incorporating HXLPE and $\mathrm{CoCr}$ using a physiologically relevant, multidirectional pin-on-disk tester. We asked: (1) Can allpolymer bearing couples involving PEEK and HXLPE have a comparable or lower wear rate than $\mathrm{CoCr}$ on HXLPE? (2) Is the wear rate of PEEK and UHMWPE bearing couples affected by the amount of cross-shear? (3) Is there a difference in wear mechanism and surface morphology for all-polymer bearing surfaces compared with UHMWPE (HXLPE) on CoCr?

\section{Materials and Methods}

Ten bearing couples consisting of three traditional bearing couples (UHMWPE-CoCr, vitamin E UHMWPE-CoCr, HXLPE [highly crosslinked UHMWPE]-CoCr) and seven allpolymer bearing couples (UHMWPE-CFR PEEK [PEEK- 
OPTIMA ${ }^{\circledR}$ Wear Performance], UHMWPE-PEEK [PEEKOPTIMA $^{\circledR}$ Natural], vitamin E UHMWPE-CFR PEEK, vitamin E UHMWPE-PEEK, vitamin E UHMWPE-BaSO4 PEEK [PEEK-OPTIMA ${ }^{\circledR}$ Image Contrast], HXL PE-CFR PEEK, HXL PE-PEEK) were tested. The UHMWPE and vitamin E UHMWPE were converted by Orthoplastics (Bacup, UK) from compression-molded GUR 1020 and GUR 1020E (Celanese, Florence, KY, USA), respectively. The HXLPE was created by subjecting the consolidated stock material to a nominal dose of $100 \mathrm{kGy}$ of gamma radiation by Steris Isomedix (Whippany, NJ, USA). The delivered dose was measured at six locations including top, bottom, front, and back surfaces. The range of delivered dose was found to be between 90.0 and $102.2 \mathrm{kGy}$. After radiation, the material was annealed at $120^{\circ} \mathrm{C}$ in air for 24 hours, consistent with a widely used stabilization protocol used by orthopaedic manufacturers [11]. The PEEK biomaterials (ie, PEEKOPTIMA $^{\circledR}$ Natural, PEEK-OPTIMA ${ }^{\circledR}$ Wear Performance, and PEEK-OPTIMA ${ }^{\circledR}$ Image Contrast) were converted into injection-molded plates by Invibio Ltd (Thornton Cleveleys, UK). The CoCr was obtained from Carpenter (Reading, PA, USA) and was produced in accordance with ASTM F90. The articulating surfaces of $\mathrm{CoCr}$ material were polished to have an average roughness $\left(\mathrm{R}_{\mathrm{a}}\right)$ of $<0.05 \mu \mathrm{m}$. Thus, all of the biomaterials used in this study were from clinically relevant grades and were produced in accordance with applicable international medical device standards. Each material in these bearing couples was machined into both pins and disks and alternated to produce 20 pin-on-disk material combinations.

The polymeric biomaterial bearing couples were tested using a 100-station pin-on-disk tester (T87 Multi-station; Phoenix Tribology Ltd, West Berkshire, UK). ASTM F732 "Standard Test Method for Wear Testing of Polymeric Materials Used in Total Joint Prostheses" was used as a guide [1]. Each pin-on-disk material combination was tested in five wear stations and one load soak station, which was used to compensate for fluid uptake (Table 1).

The static load applied to each pin was $128 \mathrm{~N}$, resulting in a nominal contact pressure of $2 \mathrm{MPa}$ (pin diameter 9 $\mathrm{mm}$ ). The lubricant used was alpha calf serum with a protein concentration of $20 \mathrm{~g} / \mathrm{L}$ (Wear Testing Fluid, HyClone, UT, USA). A lubricant chamber (volume $15 \mathrm{~mL}$ ) was mounted around each disk so that each station had an independent volume of bovine serum lubricant. Each lubricant chamber was maintained at physiological temperature $\left(37^{\circ} \pm 3^{\circ} \mathrm{C}\right)$. Before the start of the test, the disks and pins were soaked in deionized water for 56 days to allow for fluid uptake to reach equilibrium [2].

An elliptical slide track (10-mm major axis, 4-mm minor axis, circumference: $23.1 \mathrm{~mm}$ ) was used to produce multidirectional motion for 2 million cycles at $1 \mathrm{~Hz}$. The sliding speed was $23.1 \mathrm{~mm} / \mathrm{s}$. The articulating surfaces of

Table 1. Pin and disk material combinations are summarized

\begin{tabular}{|c|c|c|c|}
\hline Pin material & Disk material & Wear stations & Load soak stations \\
\hline VE UHMWPE & $\mathrm{BaSO}_{4}$ & $\mathrm{n}=5$ & $\mathrm{n}=1$ \\
\hline HXLPE & $\mathrm{CoCr}$ & $\mathrm{n}=5$ & $\mathrm{n}=1$ \\
\hline UHMWPE & $\mathrm{CoCr}$ & $\mathrm{n}=5$ & $\mathrm{n}=1$ \\
\hline VE UHMWPE & $\mathrm{CoCr}$ & $\mathrm{n}=5$ & $\mathrm{n}=1$ \\
\hline $\mathrm{CoCr}$ & HXPLE & $\mathrm{n}=5$ & $\mathrm{n}=1$ \\
\hline CFR-PEEK & HXPLE & $\mathrm{n}=5$ & $\mathrm{n}=1$ \\
\hline PEEK & HXPLE & $\mathrm{n}=5$ & $\mathrm{n}=1$ \\
\hline HXPLE & CFR-PEEK & $\mathrm{n}=5$ & $\mathrm{n}=1$ \\
\hline UHMWPE & CFR-PEEK & $\mathrm{n}=5$ & $\mathrm{n}=1$ \\
\hline VE UHMWPE & CFR-PEEK & $\mathrm{n}=5$ & $\mathrm{n}=1$ \\
\hline HXPLE & PEEK & $\mathrm{n}=5$ & $\mathrm{n}=1$ \\
\hline UHMWPE & PEEK & $\mathrm{n}=5$ & $\mathrm{n}=1$ \\
\hline VE UHMWPE & PEEK & $\mathrm{n}=5$ & $\mathrm{n}=1$ \\
\hline $\mathrm{CoCr}$ & UHMWPE & $\mathrm{n}=5$ & $\mathrm{n}=1$ \\
\hline CFR-PEEK & UHMWPE & $\mathrm{n}=5$ & $\mathrm{n}=1$ \\
\hline PEEK & UHMWPE & $\mathrm{n}=5$ & $\mathrm{n}=1$ \\
\hline $\mathrm{BaSO}_{4}$ & VE UHMWPE & $\mathrm{n}=5$ & $\mathrm{n}=1$ \\
\hline $\mathrm{CoCr}$ & VE UHMWPE & $\mathrm{n}=5$ & $\mathrm{n}=1$ \\
\hline CFR-PEEK & VE UHMWPE & $\mathrm{n}=5$ & $\mathrm{n}=1$ \\
\hline PEEK & VE UHMWPE & $\mathrm{n}=5$ & $\mathrm{n}=1$ \\
\hline
\end{tabular}


pins were fully subjected to cross-shear. Because disks were of larger diameter than pins, the contact patch on the disk varied with the position of the pin during each cycle and it was mostly exposed to unidirectional shear in the direction of pin movement. However, because the minor axis of the elliptical track was smaller than the diameter of pins, the wear track crossed itself in a limited zone in the middle of the "worn area." Therefore, cross-shear was only produced in this limited area on the disk surface. As a result of this configuration, two cross-shear scenarios were produced: pins represented the full cross-shear scenario, whereas disks represented the limited cross-shear scenario.

Every $0.25 \mathrm{MC}$, up to $2.0 \mathrm{MC}$, the wear test was stopped for interval analysis and the test specimens were removed for characterization. The pins and disks were cleaned in successive sonication and rinsing steps and dried in a desiccator using the procedure described in ASTM F1714 "Standard Guide for Gravimetric Wear Assessment of Prosthetic Hip Designs in Simulator Devices" [2]. Pins and disks were weighed using a high-precision balance with $0.01-\mathrm{mg}$ resolution. The articulating surfaces of pins and disks were photo-documented for qualitative analysis of features that may indicate active wear mechanisms. To numerically characterize the topography of articulating surfaces, the surfaces of tested pins and disks were scanned twice by white light interferometry at every interval analysis using a NewView 5000 Model 5032 equipped with advanced texture analysis software, MetroPro 7.7.0 (Zygo, Middlefield, CT, USA). At every interval analysis, the test lubricant was replaced.

Based on gravimetric measurements, the cumulative gravimetric material loss was calculated for each pin and disk after load soak correction. The volumetric wear rate (volumetric wear per million cycles) for each pin and disk was calculated by applying a linear regression algorithm at each interval analysis and dividing by the nominal density of the material. Nominal densities for the UHMWPE materials were $0.936,0.935$, and $0.935 \mathrm{mg} / \mathrm{mm}^{3}$ for vitamin E UHMWPE, HXLPE, and UHMWPE, respectively. Nominal densities for the PEEK materials were 1.420, 1.300 , and $1.360 \mathrm{mg} / \mathrm{mm}^{3}$ for CFR-PEEK, PEEK, and BaSO4 PEEK, respectively. Nominal density for $\mathrm{CoCr}$ was $9.217 \mathrm{mg} / \mathrm{mm}^{3}$. For each pin-on-disk station, the volumetric wear rates of the pin and the disk were added to calculate the combined wear rate. The wear rate for each bearing couple was calculated by averaging the combined wear rates of five test stations.

Differences in wear rates between bearing couples were evaluated using analysis of variance with a standard least squares regression model followed by Student's t-test. Statistical significance was determined using $\mathrm{p} \leq 0.05$. Sample size was sufficient to provide $80 \%$ power to detect a difference of $1.4 \mathrm{~mm}^{3} / \mathrm{MC}$ in average wear rates of bearing couples.

\section{Results}

The combined wear rates of all-polymer bearing couples tested in this study, with the exception of those with a CFR-PEEK counterface, were similar to the wear rates of conventional bearing couples (bearing couples with CoCr counterface) (Table 2). Specifically, bearing couples involving PEEK (WR: $5.1 \pm 3.7 \mathrm{~mm}^{3} / \mathrm{MC}$ ) and BaSO4 PEEK (WR: $7.6 \pm 2.0 \mathrm{~mm}^{3} / \mathrm{MC}$ ) counterfaces

Table 2. Volumetric wear rate of bearing couples*

\begin{tabular}{llll}
\hline Counterface & $\begin{array}{l}\text { Wear rate }\left(\mathrm{mm}^{3} / \mathrm{MC}\right) \\
(95 \% \text { confidence interval })\end{array}$ & Bearing couples $(\mathrm{n}=10)$ & $\begin{array}{l}\text { Bearing couple wear rate }\left(\mathrm{mm}^{3} / \mathrm{MC}\right) \\
(95 \% \text { confidence interval })\end{array}$ \\
\hline CoCr $(\mathrm{n}=30)$ & $4.1 \pm 2.7(3.2-5.1)$ & CoCr and HXLPE & $1.6 \pm 2.0(0.4-2.8)$ \\
& & CoCr and UHMWPE & $5.6 \pm 2.2(4.2-7.0)$ \\
& & CoCr and vitamin E UHMWPE & $5.2 \pm 2.0(4.0-6.5)$ \\
BaS04-PEEK $(\mathrm{n}=10)$ & $7.6 \pm 2.0(6.4-8.9)$ & BaSO4-PEEK and vitamin E UHMWPE & $7.6 \pm 2.0(0.2-1.5)$ \\
PEEK $(\mathrm{n}=30)$ & $5.1 \pm 3.7(3.7-6.4)$ & PEEK and HXLPE & $0.9 \pm 1.1(1.3-3.9)$ \\
& & PEEK and UHMWPE & $6.4 \pm 2.3(6.4-8.9)$ \\
CFR-PEEK $(\mathrm{n}=30)$ & $14.5 \pm 15.1(9.1-20.0)$ & PEEK and vitamin E UHMWPE & $7.9 \pm 2.8(4.9-7.8)$ \\
& & CFR-PEEK and HXLPE & $2.6 \pm 2.0(6.2-7.9)$ \\
& & CFR-PEEK and UHMWPE & $21.9 \pm 18.2(10.6-33.2)$ \\
& & CFR-PEEK and vitamin E UHMWPE & $19.1 \pm 12.5(11.4-26.9)$ \\
\hline
\end{tabular}

* The first two columns show bearing couples averaged by counterface; the last two columns show individual bearing couples grouped by counterface; these wear rates associated with bearing couples represent the average of two pin-on-disk combinations: material 1 as pin and material 2 as disk and vice versa; values are mean \pm SD. 
demonstrated no difference in wear rates to bearing couples with a $\mathrm{CoCr}$ counterface (WR: $4.1 \pm 2.7 \mathrm{~mm}^{3} / \mathrm{MC}$; mean difference $=0.9 \mathrm{~mm}^{3} / \mathrm{MC}, \mathrm{p}=0.61$; and mean difference $=$ $0.4 \mathrm{~mm}^{3} / \mathrm{MC}, \mathrm{p}=0.88$, respectively) with the numbers available. However, combined wear rates of bearing couples with a CFR-PEEK counterface were higher than all other polymer and conventional bearing couples (bearing couples with a $\mathrm{CoCr}$ counterface). Specifically, wear rates of bearing couples with a CFR-PEEK counterface (WR: $14.5 \pm 15.1 \mathrm{~mm}^{3} / \mathrm{MC}$ ) were higher than those of bearing couples involving a PEEK (WR: $5.1 \pm 3.7 \mathrm{~mm}^{3} / \mathrm{MC}$ ) or CoCr (WR: $4.1 \pm 2.7 \mathrm{~mm}^{3} / \mathrm{MC}$ ) counterface (mean difference $=9.5 \mathrm{~mm}^{3} / \mathrm{MC}, \mathrm{p}<0.001 ;$ and mean difference $=$ $10.4 \mathrm{~mm}^{3} / \mathrm{MC}, \mathrm{p}<0.001$, respectively).

The amount of cross-shear did not affect the wear rate of PEEK or HXLPE bearing materials when tested as a pin or disk (PEEK: $0.3 \pm 0.1 \mathrm{~mm}^{3} / \mathrm{MC}$ for pin and $0.0 \pm 1.0$ $\mathrm{mm}^{3} / \mathrm{MC}$ for disk, mean difference $=0.3 \mathrm{~mm}^{3} / \mathrm{MC}, \mathrm{p}=$ 0.23 ; and HXLPE: $1.3 \pm 1.0 \mathrm{~mm}^{3} / \mathrm{MC}$ for pin and $2.1 \pm$ $2.2 \mathrm{~mm}^{3} / \mathrm{MC}$ for disk, mean difference $=0.8 \mathrm{~mm}^{3} / \mathrm{MC}, \mathrm{p}=$ 0.24); however, the wear rate of UHMWPE was affected by the amount of cross-shear when UHWMPE was used as a pin or disk $\left(15.3 \pm 13.0 \mathrm{~mm}^{3} / \mathrm{MC}\right.$ for pin and $5.6 \pm 2.2$ $\mathrm{mm}^{3} / \mathrm{MC}$ for disk, mean difference $=9.6 \mathrm{~mm}^{3} / \mathrm{MC}, \mathrm{p}<$ 0.001) (Fig. 1A-B).

UHMWPE demonstrated an adhesive abrasive wear mechanism when coupled with neat PEEK or $\mathrm{CoCr}$ and an abrasive wear mechanism when coupled with CFR-PEEK. For example, surfaces of UHMWPE pins appeared burnished and had protuberances when coupled with PEEK or $\mathrm{CoCr}$ disks at 1.0 MC, whereas they had a rougher appearance, demonstrating multidirectional scratching, when coupled with CFR-PEEK (Fig. 2). Surfaces of HXLPE pins appeared rough and scratched when coupled with $\mathrm{CoCr}$ disks at $1.0 \mathrm{MC}$, whereas they appeared rough but not scratched when coupled with PEEK and CFRPEEK disks (Fig. 3). According to surface interferometry results, the surface roughness of all tested pins and disks followed similar patterns. An initial decrease in roughness was observed, consistent with burnishing of the initial machined surfaces. After approximately 1.0 MC of testing, a slight increase in surface roughness was observed (Fig. 4).

\section{Discussion}

All-polymer bearings have been proposed for orthopaedic bearings, but little is known regarding their tribologic performance compared with traditional bearing couples incorporating UHMWPE, HXLPE, and/or CoCr. We designed an experiment using a 100-station multidirectional pin-on-disk tester to determine whether all-polymer bearing couples incorporating PEEK have a comparable or lower wear than CoCr-on-HXLPE bearing couples. We also wanted to explore the effect of cross-shear and the wear rate of all-polymer PEEK bearings. Two cross-shear conditions were tested when a bearing material was tested as a pin or disk. In our experiment, we found that PEEKon-HXLPE bearings exhibit comparable wear rates to the CoCr-on-HXLPE bearing couples. These bearings were insensitive to cross-shear and we found no difference in the morphology of the HXLPE bearing materials.

We would like to highlight some limitations of our study. First, the multidirectional motion imparted by the pin-on-disk testers is simplified and idealized. Although multidirectional pin-on-disk testers have been shown to be capable of ranking bearing couples in terms of their predictive in vivo wear rates, full joint simulator testing is required to better evaluate physiologically relevant wear mechanisms of total joint arthroplasty components [3]. For this reason, the reported wear rates are only applicable in ranking bearing couples and point specifically toward further evaluation of PEEK-on-HXLPE bearing couples in more realistic models such as hip or knee simulators. Second, as a result of the idealized motion and simplified geometry of contact on a pin-on-disk tester, frictional heat generation and its possible effects such as adherence of lubricant proteins may not be physiologically relevant. Furthermore, the elliptical motion of the specimens on the tester allowed for only full and limited levels of cross-shear (pin and disk, respectively), and a no cross-shear condition (linear reciprocating motion) was not tested in this study. We did not investigate this limiting condition, because even in the knee, at least some cross-shear is observed, even if it is reduced when compared with the hip [23]. Another limitation was that the temperature or state of the lubricant resulting from anticipated temperature rise was not measured in this study. However, a temperature rise resulting from frictional heat was expected in all-polymer bearing couples based on our previous study (1st International PEEK Meeting, Philadelphia, PA, USA, 2013). Being able to detect a difference of $1.4 \mathrm{~mm}^{3} / \mathrm{MC}$ in wear rates of bearing couples with $80 \%$ power was sufficient because the difference between the two conventional bearing couples, which have distinct clinical wear performances, namely UHMWPE pin-on-CoCr disk (WR: $7.3 \pm$ $1.1 \mathrm{~mm}^{3} / \mathrm{MC}$ ) and HXLPE pin-on-CoCr disk (WR: $0.9 \pm$ $1.1 \mathrm{~mm}^{3} / \mathrm{MC}$ ), was $6.4 \mathrm{~mm}^{3} / \mathrm{MC}$ in this study (Table 3 ).

The wear rates for all-polymer bearings with PEEK, excluding CFR-PEEK, were comparable to the conventional bearings in this study, namely UHMWPE-CoCr and HXLPE-CoCr, but most promising when articulating PEEK with HXLPE. PEEK and HXLPE bearing couples had a wear rate of $0.9 \pm 1.1 \mathrm{~mm}^{3} / \mathrm{MC}$. However, the wear rate of PEEK and HXLPE bearing couples was not 
Fig. 1A-B Combined wear rates of all-polymer bearings and conventional bearings with $\mathrm{CoCr}$ against polyethylene grouped by UHMWPE or HXLPE counterface are shown. Bearing couples with polyethyelene as pin (A) or disk (B) are plotted separately. Vitamin E UHMWPE and UHMWPE specimens were pooled together. (BaSO4-PEEK was not tested against HXLPE in this study.)

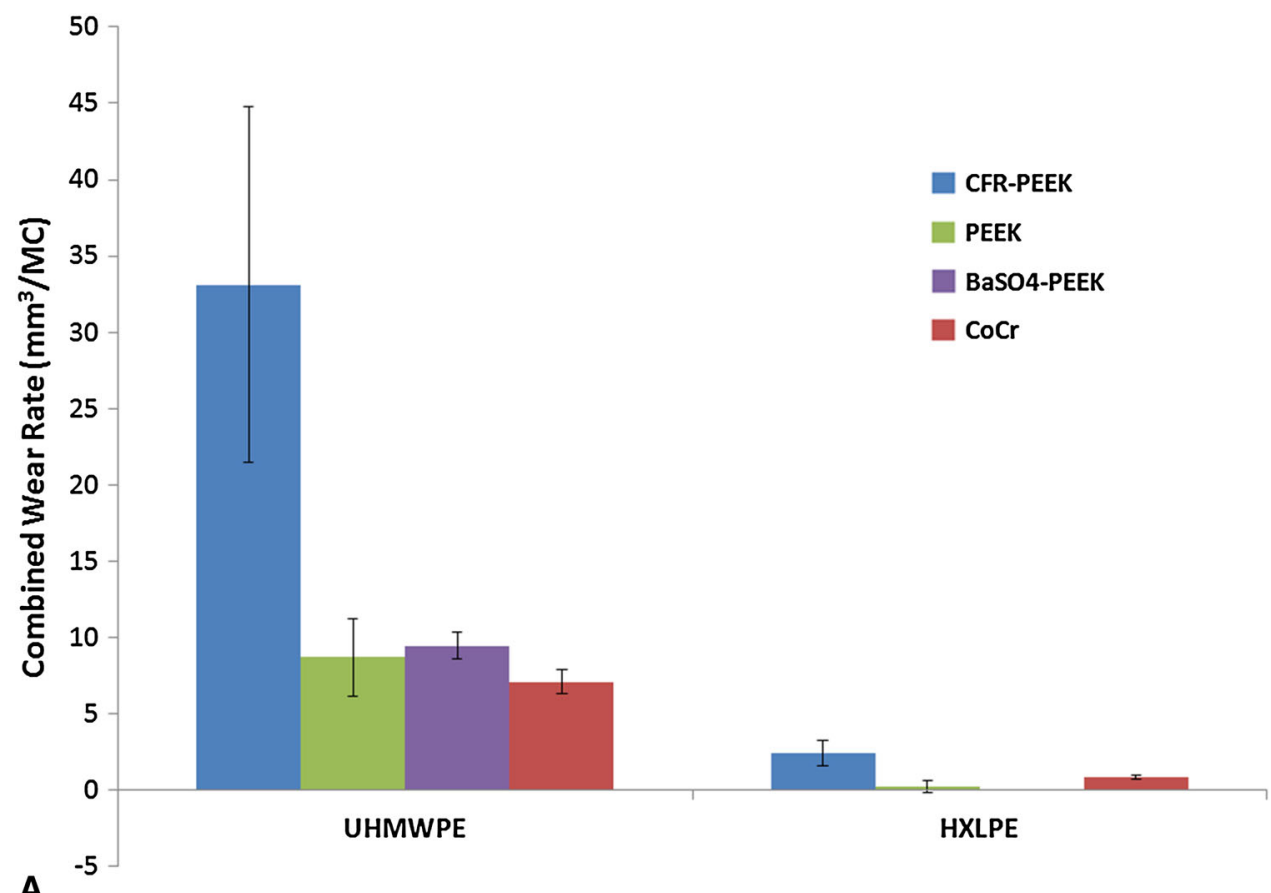

A



different than the wear rate of $\mathrm{CoCr}$ and HXLPE bearing couples $\left(1.6 \pm 2.0 \mathrm{~mm}^{3} / \mathrm{MC}\right.$, mean difference $=0.7 \mathrm{~mm}^{3} /$ MC, $\mathrm{p}=0.36)$ (Table 2).

Previous studies have investigated the wear rate of allpolymer bearings using pin-on-disk testing. For example, East et al. [6] reported an average wear factor of $0.0134 \times$ $10^{-6} \mathrm{~mm}^{3} / \mathrm{Nm}$ for a PEEK-on-HXLPE UHMWPE (100
kGy GUR1020) bearing couple. The average wear factor of a PEEK pin on HXLPE disk bearing couple in our study was $0.29 \pm 0.37 \times 10^{-6} \mathrm{~mm}^{3} / \mathrm{Nm}$ (wear factor $=$ wear rate/ [load $\times$ distance per cycle]). A possible explanation for the lower wear factor reported by East et al. [6] is that the contact area of their pins was much smaller than the current study (pin diameter of $5 \mathrm{~mm}$ compared with $9 \mathrm{~mm}$ in our 


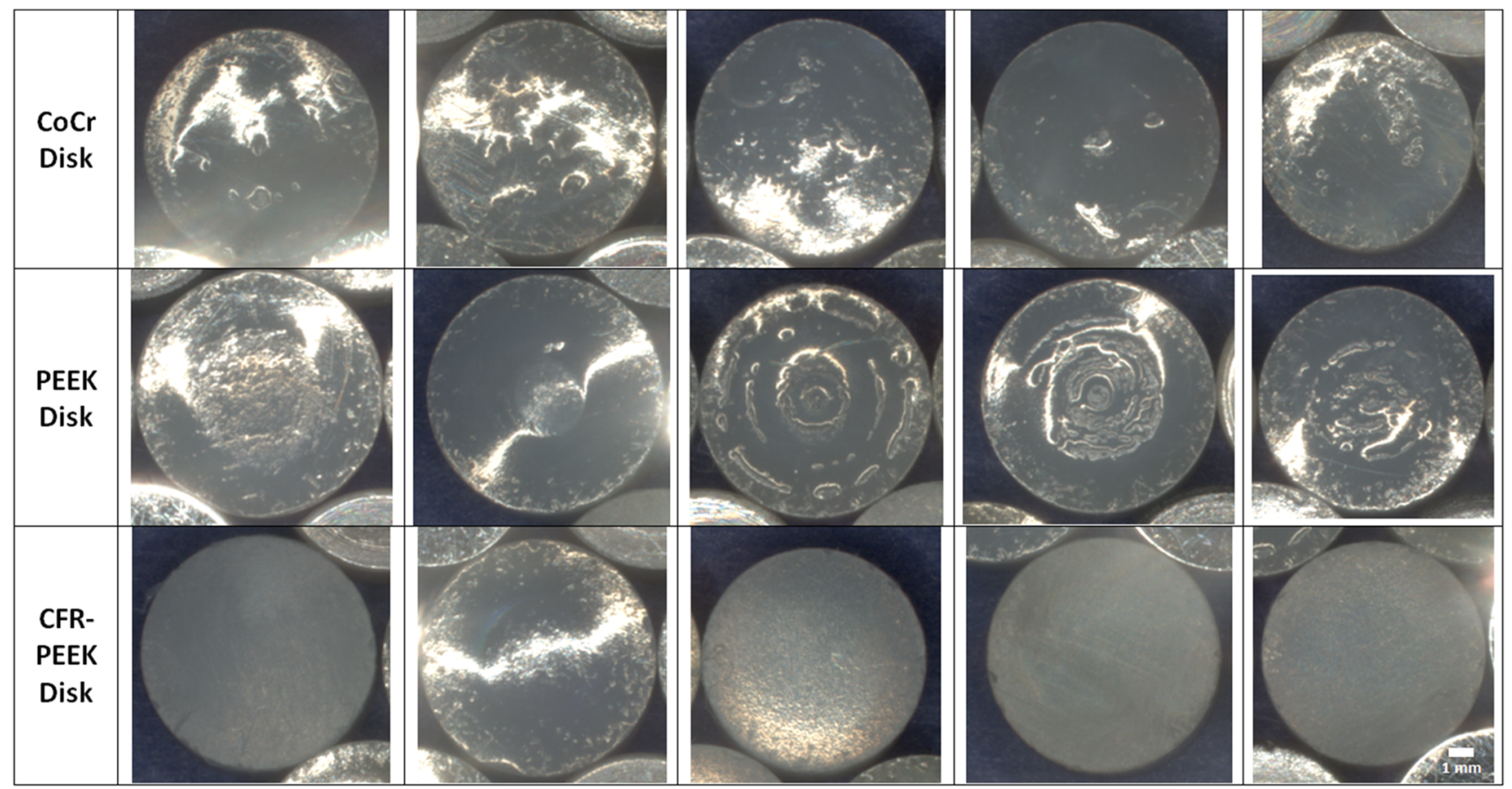

Fig. 2 Surfaces of UHMWPE pins grouped by counterface after 1.0 MC of testing are shown. Burnishing and protuberances were observed when UHMWPE pins were coupled with PEEK or $\mathrm{CoCr}$ disks. When coupled with CFR-PEEK, the UHMWPE surfaces had a rougher appearance.

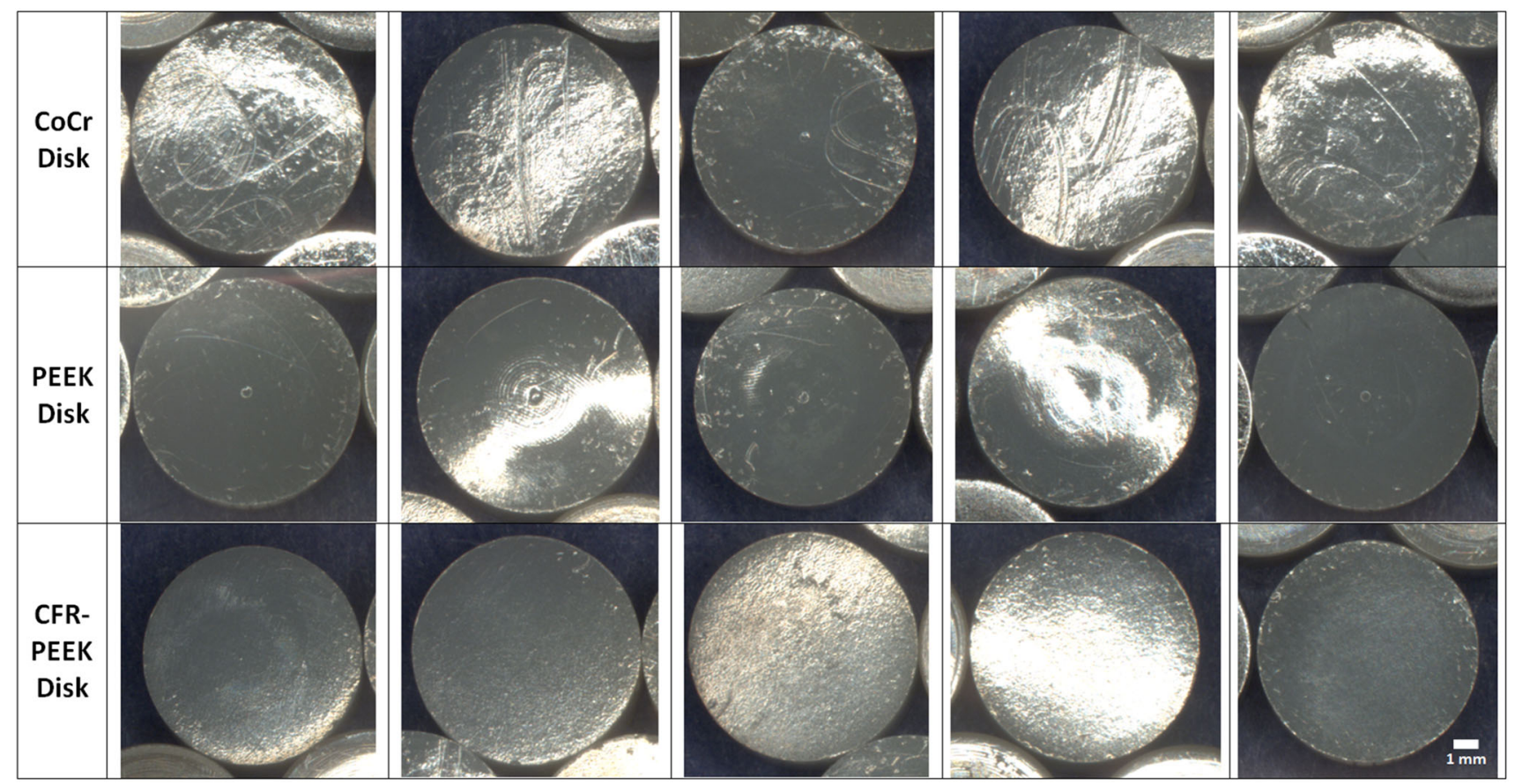

Fig. 3 Surfaces of HXLPE pins grouped by counterface after 1.0 MC of testing are shown. Surfaces of HXLPE had a rough appearance against all counterfaces. Scratches were only observed when coupled with $\mathrm{CoCr}$.

study). The dependence of polymer wear on contact area was previously reported for UHMWPE on a pin-on-disk apparatus [16]. The wear rate of UHMWPE was reported to correlate with the number of asperities in contact and, hence, contact area. Also, East et al. [6] had linearly reciprocating disks coupled with rotation of pins around 



Fig. 4A-B Average surface roughness ( \pm SD) of UHMWPE $(\mathbf{A})$ and HXLPE $(\mathbf{B})$ pins grouped by counterface is shown. Five pins in each group were scanned twice at each time point.

their axis, which may impart a different sliding vector compared with the elliptical motion created by the linear $\mathrm{XY}$ stage of the 100-station pin-on-disk tester used in this study. For CFR-PEEK on HXLPE bearing couples, East et al. [6] reported $0.052-0.138 \times 10^{-6} \mathrm{~mm}^{3} / \mathrm{Nm}$ for CFRPEEK pins and $49.3-87.5 \times 10^{-6} \mathrm{~mm}^{3} / \mathrm{Nm}$ for HXLPE disks. The average wear factor of the CFR-PEEK pin-onHXLPE disk bearing couple in our study was $0.88 \pm 0.69$ $\times 10^{-6} \mathrm{~mm}^{3} / \mathrm{Nm}$. Our results also showed that CFR-PEEK on HXLPE led to a higher wear compared with PEEK on
HXLPE. The magnitudes were lower compared with East et al. [6]. Again, these comparisons underline the importance of testing bearing couples simultaneously under identical test conditions to compare their wear rates. In another study, Langohr et al. [13] tested PEEK and CFRPEEK self-mating pin and disk bearing couples. The pins were $9.5 \mathrm{~mm}$ in diameter (compared with $9 \mathrm{~mm}$ in the current study) and traveled $17 \mathrm{~mm}$ (compared with $23 \mathrm{~mm}$ in the current study) while rotating around their axes. They reported an average wear factor of $0.64 \pm 0.13 \times 10^{-6}$ 
Table 3. Volumetric wear rate grouped by material for pin and disk configurations*

\begin{tabular}{|c|c|c|c|c|}
\hline Pin material & $\begin{array}{l}\text { Volumetric wear rate } \\
\left(\mathrm{mm}^{3} / \mathrm{MC}\right) \\
(95 \% \text { confidence interval })\end{array}$ & Disk material & $\begin{array}{l}\text { Volumetric wear } \\
\text { rate }\left(\mathrm{mm}^{3} / \mathrm{MC}\right) \\
(95 \% \text { confidence interval })\end{array}$ & $\begin{array}{l}\text { Combined wear } \\
\text { rate }\left(\mathrm{mm}^{3} / \mathrm{MC}\right)(95 \% \\
\text { confidence interval })\end{array}$ \\
\hline UHMWPE & $7.3 \pm 1.0(6.4-8.2)$ & $\mathrm{CoCr}$ & $0.0 \pm 0.0(0.0-0.1)$ & $7.3 \pm 1.0(6.4-8.2)$ \\
\hline UHMWPE & $8.2 \pm 0.9(7.4-9.0)$ & PEEK & $-0.2 \pm 0.2(-0.4$ to -0.1$)$ & $8.0 \pm 1.0(7.1-8.9)$ \\
\hline UHMWPE & $36.5 \pm 14.8(23.5-49.5)$ & CFR-PEEK & $-0.2 \pm 0.1(-0.3$ to -0.1$)$ & $36.3 \pm 14.9(23.3-49.4)$ \\
\hline Vitamin-E UHMWPE & $6.8 \pm 0.3(6.5-7.1)$ & $\mathrm{CoCr}$ & $0.0 \pm 0.0(0.0-0.0)$ & $6.8 \pm 0.3(6.5-7.1)$ \\
\hline Vitamin-E UHMWPE & $9.7 \pm 0.9(8.9-10.5)$ & BaSO4 PEEK & $-0.3 \pm 0.0(-0.3$ to -0.2$)$ & $9.4 \pm 0.9(8.7-10.2)$ \\
\hline Vitamin-E UHMWPE & $8.7 \pm 1.6(7.4-10.1)$ & PEEK & $0.7 \pm 2.0(-1.1-2.4)$ & $9.4 \pm 3.5(6.4-12.5)$ \\
\hline Vitamin-E UHMWPE & $29.4 \pm 7.6(22.8-36.1)$ & CFR-PEEK & $0.5 \pm 1.1(-0.5-1.4)$ & $29.9 \pm 7.6(23.3-36.6)$ \\
\hline HXLPE & $0.9 \pm 0.1(0.8-1.0)$ & $\mathrm{CoCr}$ & $0.0 \pm 0.0(0.0-0.0)$ & $0.9 \pm 0.1(0.7-1.0)$ \\
\hline HXLPE & $0.5 \pm 0.1(0.4-0.6)$ & PEEK & $-0.2 \pm 0.3(-0.5-0.0)$ & $0.2 \pm 0.4(-0.1-0.5)$ \\
\hline HXLPE & $2.5 \pm 0.8(1.9-3.2)$ & CFR-PEEK & $-0.1 \pm 0.1(-0.3-0.0)$ & $2.4 \pm 0.8(1.7-3.1)$ \\
\hline PEEK & $0.2 \pm 0.0(0.1-0.2)$ & UHMWPE & $4.6 \pm 1.9(2.9-6.3)$ & $4.7 \pm 2.0(3.0-6.4)$ \\
\hline PEEK & $0.3 \pm 0.2(0.1-0.5)$ & Vitamin E UHMWPE & $6.2 \pm 0.4(5.8-6.5)$ & $6.5 \pm 0.3(6.2-6.7)$ \\
\hline PEEK & $0.3 \pm 0.1(0.2-0.3)$ & HXLPE & $1.2 \pm 1.2(0.2-2.3)$ & $1.5 \pm 1.2(0.4-2.6)$ \\
\hline CFR-PEEK & $0.0 \pm 0.0(0.0-0.0)$ & UHMWPE & $7.4 \pm 2.4(5.4-9.5)$ & $7.5 \pm 2.3(5.4-9.5)$ \\
\hline CFR-PEEK & $0.2 \pm 0.1(0.1-0.2)$ & Vitamin E UHMWPE & $8.2 \pm 1.9(6.6-9.9)$ & $8.4 \pm 1.9(6.8-10.0)$ \\
\hline CFR-PEEK & $0.2 \pm 0.2(0.0-0.4)$ & HXLPE & $2.6 \pm 2.7(0.2-5.0)$ & $2.8 \pm 2.9(0.2-5.4)$ \\
\hline BaSO4 PEEK & $0.3 \pm 0.1(0.2-0.4)$ & Vitamin E UHMWPE & $5.5 \pm 0.6(5.0-6.1)$ & $5.8 \pm 0.6(5.3-6.3)$ \\
\hline $\mathrm{CoCr}$ & $0.0 \pm 0.0(0.0-0.0)$ & UHMWPE & $3.9 \pm 1.6(2.5-5.2)$ & $3.9 \pm 1.6(2.5-5.2)$ \\
\hline $\mathrm{CoCr}$ & $0.0 \pm 0.0(0.0-0.0)$ & Vitamin E UHMWPE & $3.6 \pm 1.5(2.3-5.0)$ & $3.6 \pm 1.5(2.3-5.0)$ \\
\hline $\mathrm{CoCr}$ & $0.0 \pm 0.0(0.0-0.0)$ & HXLPE & $2.3 \pm 2.7(0.0-4.7)$ & $2.4 \pm 2.7(0.0-4.7)$ \\
\hline
\end{tabular}

* Nominal densities for UHMWPE were $0.936,0.935$, and $0.935 \mathrm{mg} / \mathrm{mm}^{3}$ for vitamin E, highly crosslinked, and conventional UHMWPE, respectively; nominal densities for PEEK were 1.420, 1.300, and $1.360 \mathrm{mg} / \mathrm{mm}^{3}$ for CFR-PEEK, PEEK, and BaSO4 PEEK, respectively; nominal density for $\mathrm{CoCr}$ was $9.217 \mathrm{mg} / \mathrm{mm}^{3}$; values are mean $\pm \mathrm{SD}$.

$\mathrm{mm}^{3} / \mathrm{Nm}$ and $0.13 \pm 0.12 \times 10^{-6} \mathrm{~mm}^{3} / \mathrm{Nm}$ for PEEK and CFR-PEEK, respectively. These wear factors are comparable to the wear factors reported in the current study, although some test parameters are different between the two studies: the contact area is larger in Langohr et al. [13]; the slide track is different in nature (pins translate while rotating); and the bearing couples were self-mating PEEKon-PEEK and CFR-PEEK-on-CFR-PEEK.

The amount of cross-shear was found to have no effect on the wear rates of PEEK and HXLPE specimens. Additionally, the current study confirmed the wear rate of UHMWPE was affected by cross-shear, which has been previously reported by others [3]. Laux and Schwartz [14] reported that the wear rate of PEEK increased with multidirectional sliding; the smallest wear rate was reported with reciprocating motion. However, the specimens in the Laux and Schwartz study were articulated in the absence of a lubricant. Dry articulation may affect the wear mechanisms and they may not be physiologically relevant. For instance, dry articulation of UHMWPE was shown to lead to delamination and polyethylene transfer [5], which are not observed in explants. Furthermore, Laux and Schwartz reported transfer films observable with the naked eye as a result of dry lubrication. Grupp et al. [8] tested CFRPEEK-on-CoCr unicondylar knee arthroplasty devices with calf serum as a lubricant on a joint simulator and reported only visible scratching on the surfaces of $\mathrm{CoCr}$ specimens, similar to what they observed with UHMWPE-on-CoCr articulation, and did not observe transfer films.

The surface morphology and roughness of UHMWPE and HXLPE pins were examined specifically because UHMWPE and HXLPE pins were coupled with both PEEK and $\mathrm{CoCr}$ counterfaces, which was assumed to represent a reference and higher temperature scenario in our study, respectively, based on our previous study. Because surface features on UHMWPE and HXLPE specimens did not differ when they articulated against a $\mathrm{CoCr}$ or PEEK counterface, this indicated that similar wear mechanisms were promoted with these bearing couples despite anticipated changes in contact surface temperatures. East et al. [6] reported possible deposition of transfer films of PEEK on HXLPE surfaces that were visible in micrographs or detectable by Fourier transform infrared spectroscopy. The authors postulated that PEEK could have attached itself to 
HXLPE surfaces. In our study, we observed no evidence of adherent transfer film deposited on specimens that could be detected visually by a low-magnification microscope or by noncontact interferometry. Scholes and Unsworth [22] tested PEEK and CFR-PEEK self-mating couples on a multidirectional pin-on-plate machine. The authors used white light interferometry and reported that the plates initially became smoother and then roughened slightly, similar to results from our current study [22]. However, it was reported that the pins became smoother during their test, whereas the pins from our study showed a pattern of decreasing roughness initially with an increasing roughness pattern toward the end of the test based on semiquantitative analysis. Scholes and Unsworth did not report observations of transfer film visually or by noncontact interferometry.

In conclusion, our data suggest that all-polymer bearings, especially PEEK-HXLPE bearing couples, may represent a viable alternative to traditional CoCr-HXLPE and CoCr-UHWMPE bearings with respect to their wear performance. However, not all of the polymer-on-polymer bearings showed equal promise. For example, CFR-PEEK was consistently ranked as exhibiting the highest wear rates when it was mated with any of the UHMWPEs and thus may not be as promising as some of the other alternative PEEK bearings we investigated. In particular, PEEK and HXLPE bearing materials tested in this study were found to be insensitive to cross-shear and we also found nothing to suggest that anticipated increases in temperature affect the morphology of the UHMWPE and HXLPE bearing materials in all-polymer and traditional bearing couples. Consequently, the findings from our screening experiment warrant further exploration of certain all-polymer bearing couples in joint simulator tests to continue to rigorously test them for orthopaedic applications.

Acknowledgments We thank Invibio for supporting this study.

\section{References}

1. ASTM F732-00. Standard Test Method for Wear Testing of Polymeric Materials Used in Total Joint Prostheses. West Conshohocken, PA, USA: ASTM International; 2011.

2. ASTM F1714-96. Standard Guide for Gravimetric Wear Assessment of Prosthetic Hip Designs in Simulator Devices. West Conshohocken, PA, USA: ASTM International; 2013.

3. Baykal D, Siskey RS, Haider H, Saikko V, Ahlroos T, Kurtz SM. Advances in tribological testing of artificial joint biomaterials using multidirectional pin-on-disk testers. J Mech Behav Biomed Mater. 2014;31:117-134.

4. Blunn G, Walker P, Joshi A, Hardinge K. The dominance of cyclic sliding in producing wear in total knee replacements. Clin Orthop Relat Res. 1991:273:253-260.
5. Dumbleton J, Shen C. The wear behavior of ultrahigh molecular weight polyethylene. Wear. 1976;37:279-289.

6. East RH, Briscoe A, Unsworth A. Wear of PEEK-OPTIMA(R) and PEEK-OPTIMA(R)-Wear Performance articulating against highly cross-linked polyethylene. Proc Inst Mech Eng [H]. 2015;229:187-193.

7. Greenbaum ES, Burroughs BB, Harris WH, Muratoglu OK. Effect of lipid absorption on wear and compressive properties of unirradiated and highly crosslinked UHMWPE: an in vitro experimental model. Biomaterials. 2004;25:4479-4484.

8. Grupp TM, Utzschneider S, Schröder C, Schwiesau J, Fritz B, Maas A, Blömer W, Jansson V. Biotribology of alternative bearing materials for unicompartmental knee arthroplasty. Acta Biomater. 2010;6:3601-3610.

9. Haider H, Baykal D. Wear assessment of UHMWPE with pin-ondisc testing. In: Kurtz SM, ed. UHMWPE Biomaterials Handbook. Waltham, MA, USA: Elsevier; 2016.

10. Kurtz SM. PEEK Biomaterials Handbook. Waltham, MA, USA: Elsevier; 2011.

11. Kurtz SM. Compendium of HXLPEs. In: Kurtz SM, ed. UHMWPE Biomaterials Handbook. Waltham, MA, USA: Elsevier; 2016.

12. Kurtz SM. UHMWPE Biomaterials Handbook: Ultra High Molecular Weight Polyethylene in Total Joint Replacement and Medical Devices. Waltham, MA, USA: Elsevier; 2016.

13. Langohr G, Gawel H, Medley J. Wear performance of all-polymer PEEK articulations for a cervical total level arthroplasty system. Proc Inst Mech Eng [J]. 2011;225:499-513.

14. Laux K, Schwartz C. Influence of linear reciprocating and multidirectional sliding on PEEK wear performance and transfer film formation. Wear. 2013;301:727-734.

15. Lu Z, McKellop H. Frictional heating of bearing materials tested in a hip joint wear simulator. Proc Inst Mech Eng [H]. 1997;211:101-108.

16. Mazzucco D, Spector M. Effects of contact area and stress on the volumetric wear of ultrahigh molecular weight polyethylene. Wear. 2003;254:514-522.

17. Muratoglu OK, Bragdon CR, O'Connor DO, Jasty M, Harris WH, Gul R, McGarry F. Unified wear model for highly crosslinked ultra-high molecular weight polyethylenes (UHMWPE). Biomaterials. 1999;20:1463-1470.

18. Pritchett J. Heat generated by hip resurfacing prostheses: an in vivo pilot study. J Long Term Eff Med Implants. 2011;21:55.

19. Saikko V. A multidirectional motion pin-on-disk wear test method for prosthetic joint materials. J Biomed Mater Res. 1998;41:58-64.

20. Scholes S, Unsworth A. The wear properties of CFR-PEEKOPTIMA articulating against ceramic assessed on a multidirectional pin-on-plate machine. Proc Inst Mech Eng [H]. 2007;221:281-289.

21. Scholes S, Unsworth A. Wear studies on the likely performance of CFR-PEEK/CoCrMo for use as artificial joint bearing materials. J Mater Sci Mater Med. 2009;20:163-170.

22. Scholes S, Unsworth A. The wear performance of PEEKOPTIMA based self-mating couples. Wear. 2010;268:380-387.

23. Wang A, Essner A, Polineni V, Stark C, Dumbleton J. Lubrication and wear of ultra-high molecular weight polyethylene in total joint replacements. Tribol Int. 1998;31:17-33.

24. Wang A, Polineni V, Essner A, Sokol M, Sun D, Stark C, Dumbleton J. The significance of nonlinear motion in the wear screening of orthopaedic implant materials. J Test Eval. 1997;25:239-245. 